\title{
Prognostic factors for overall survival with targeted therapy in Chinese patients with metastatic renal cell carcinoma
}

\author{
Juping Zhao, MD, ${ }^{*}$ Xin Huang, MD; ${ }^{*}$ Fukang Sun, MD; ${ }^{*}$ Renyi Ma, MD; ${ }^{\dagger}$ Haofei Wang, MD, ${ }^{*}$ Kun Shao, MD; \\ Yu Zhu, MD;" Wenlong Zhou, MD; " Zhaoping Xu, MD;" Zhoujun Shen, PhD*
}

Juping Zhao and Xin Huang contributed equally to this work.

*Department of Urology, Ruijin Hospital, Shanghai JiaoTong University School of Medicine, Shanghai 200025, China; †Department of Pathology, Ruiijin Hospital, Shanghai JiaoTong University School of Medicine, Shanghai 200025, China

Cite as: Can Urol Assoc J 2014;8(11-12):e821-7. http://dx.doi.org/10.5489/cuaj.2096 Published online November 24, 2014.

\section{Abstract}

Introduction: We wanted to identify the prognostic factors for overall survival (OS) in Chinese patients with metastatic renal cell carcinoma (mRCC) treated with first-line targeted therapy (sorafenib or sunitinib).

Methods: We retrospectively reviewed clinical data from 119 mRCC patients administered sorafenib or sunitinib at the Ruijin Hospital since 2007. OS rates were calculated by the Kaplan-Meier method. Each variable was investigated univariately and then multivariately using a stepwise algorithm. A multivariate Cox regression model analyzed baseline variables for prognostic significance.

Results: The mean patient age was $57 \pm 12$ years; 37 patients (31\%) received sorafenib and $82(69 \%)$ received sunitinib. The mean OS was $22.7 \pm 15.6$ months (range: $2.8-68.7$ ). OS rates at year 1,3 and 5 were $74 \%, 57 \%$, and $36 \%$, respectively. Univariate analysis identified significant negative prognostic factors $(p<0.05)$ as Eastern Cooperative Oncology Group (ECOG) performance status $\geq 2$, symptoms, no prior nephrectomy, microscopic necrosis, $\geq 2$ metastatic sites, presence of liver, bone, or pancreas metastasis, hemoglobin less than the lower limit of normal(female $<115 \mathrm{~g} / \mathrm{L}$, male $<130 \mathrm{~g} / \mathrm{L}$ ), and serum alkaline phosphatase greater than the upper limit of normal (126 IU/L) at baseline, as well as a relative dose intensity of targeting agents in the first month (1M-RDI) of $<50 \%$. Multivariate analysis of OS identified 4 independent predictors: no symptoms, no bone or pancreas metastasis, and 1M-RDI of targeting agents $(\geq 50 \%)$.

Conclusions: With targeted therapy, there is some change in the prognostic factors for $\mathrm{mRCC}$ and target drug therapies (1M-RDI $\geq 50 \%$ ) play an important role in the prognosis of $\mathrm{mRCC}$. Continued progress in the identification of patient-specific prognostic factors for $\mathrm{mRCC}$ will require further advances in the understanding of tumour biology.

\section{Introduction}

Metastatic renal cell carcinoma (mRCC) is generally unresponsive to conventional chemotherapy and hormonal therapy, and treatment with cytokines results in an only modest response rate. In recent years, angiogenesis-targeted therapies, such as with sorafenib and sunitinib, have improved the prognosis of mRCC. ${ }^{1,2}$ Prognostic factors are used in mRCC clinical trial design and interpretation, risk-directed treatment, and patient counselling; predictive models have been developed and have been applied to the conduct of clinical trials. One model developed at the Memorial SloanKettering Cancer Center (MSKCC) classifies patients as at favourable risk, intermediate risk, or poor risk according to the number of risk factors predictive of survival. ${ }^{3}$ In this model, factors predicting shorter survival time include: time from diagnosis to start of systemic therapy of $<1$ year, elevated levels of lactate dehydrogenase (LDH) and corrected serum calcium, anemia, and low performance status. ${ }^{4}$ The MSKCC model was independently validated by investigators at the Cleveland Clinic ${ }^{5}$ and is used for the study and interpretation of targeted drug therapies. In a recently proposed nomogram for mRCC, risk grouping guides treatment. ${ }^{6}$ For example, sunitinib is cited as a preferred treatment option for mRCC patients with favourable risk or intermediate risk. In contrast, temsirolimus is recommended for RCC patients with features of poor risk. ${ }^{7,8}$

Sorafenib and sunitinib have been available for use in mRCC in China since 2007, which has made clinical decision-making more complex. Understanding and identifying prognostic factors are important for the development and evaluation of new treatments. Overall survival (OS) is a reliable endpoint for assessing the efficacy of mRCC with targeted therapy; ${ }^{4}$ so far, however, factors predictive for OS with targeting agents have not been fully assessed, especially in China. 
In this study, we primarily analyzed clinical data from Ruijin Hospital for Chinese patients with mRCC treated with first-line targeted therapy (sorafenib or sunitinib) to identify relevant prognostic factors for OS, using MSKCC risk groups. $^{4}$

\section{Methods}

\section{Patient selection}

We retrospectively reviewed patients with RCC enrolled at the Ruijin Hospital from November 2007 to November 2013. Key patient eligibility criteria included histological confirmation of RCC, measurable metastatic lesions, as well as adequate hepatic, renal, and cardiac functions. All patients provided signed informed consent. The endpoint of this study was OS. Routine studies included the following: disease history, complete blood count, hepatic function, renal function, and imaging studies to assess measurable metastatic lesions. Imaging was performed at baseline and repeated after every 2 cycles of therapy.

We excluded patients with the following: prior myocardial infarction; unstable or severe angina; coronary or peripheral artery bypass graft; cerebrovascular accident, transient ischemic attack, or pulmonary embolism occurring within 1 year before study entry; and any prior systemic regimens (e.g., radiotherapy, chemotherapy or immunotherapy) for RCC. Patients with an active bleeding diathesis or those requiring systemic anticoagulation with warfarin were also excluded.

According to our RCC database, there were 702 RCC patients from November 2007 to November 2013. There were 131 patients diagnosed as mRCC and 119 patients received targeted therapy. Twelve patients were excluded from this study for prior myocardial infarction $(n=2)$; cerebrovascular accident $(\mathrm{n}=3)$; pulmonary embolism $(\mathrm{n}=1)$; prior systemic regimens (cytokines) for RCC $(n=5)$; and severe insufficient cardiac function $(n=1)$.

\section{Study design}

Sorafenib or sunitinib therapy was initiated when patients had recovered from palliative nephrectomy or when RCC was histologically confirmed by needle puncture biopsy. Starting FDA-approved doses were sorafenib at $400 \mathrm{mg}$ orally twice daily continuously in a 4-week cycle and sunitinib at $50 \mathrm{mg}$ orally daily in a 6 -week cycle (4 weeks on, 2 weeks off). Patients who experienced a toxicity of grade 3 or higher related to the targeting agent had their doses reduced by half. Dose re-escalation was allowed if toxicity recovered to below grade 2 within 4 weeks. For treatment-emergent toxicities of grade 3 or higher, therapy was withheld until resolution to grade 1 or lower. Patients were removed from therapy at the onset of RECIST (Response Evaluation Criteria In Solid Tumors) defined disease progression or unacceptable toxicity. Unacceptable toxicity was defined as when treatment was delayed for $\geq 4$ weeks for recovery to a permissible level of toxicity despite 2-dose level reductions. Tumour response was assessed using RECIST criteria (version 1.0). The severity of adverse events was assessed using the $\mathrm{NCl}$ (National Cancer Institute) CTCAE (Common Terminology Criteria for Adverse Events) (version 3.0).

This trial was an open-label, single centre study. All patients were first informed of the advantages and disadvantages of sorafenib and sunitinib; patients were then given one of the medications as their first-line therapy. This study was approved by the ethics committee at our hospital.

\section{Statistical analysis}

Separate analyses were carried out to identify prognostic factors for OS. Prognostic variables were based on routine clinical data. All laboratory values were examined as continuous variables. All other baseline factors were examined as discrete variables. Each variable was first investigated by univariate analysis, and then by a multivariate analysis with a stepwise algorithm. Additional elimination was applied to identify significant variables at the level of $p<0.05$. A multivariate Cox regression model was used to analyze potential baseline prognostic variables for OS. All statistical analyses were performed with the use of the statistical software SPSS version 20.0 (SPSS Inc., Chicago, IL). The analyses explored previously identified prognostic factors, such as those used in the MSKCC risk groups, ${ }^{4}$ as well as other factors (Table 1 ).

\section{Results}

\section{Patients}

This retrospective clinical study enrolled 119 patients, all with histologically confirmed RCC, who received targeted therapy. The mean ( \pm standard deviation) follow-up was $22.7 \pm 15.6$ months (range: $2.8-68.7$ ). There were 92 men and 27 women, with mean age of $57.1 \pm 11.9$ years (range: $28-82)$. There were 37 patients (31\%) treated with sorafenib and 82 patients (69\%) treated with sunitinib.

Most patients (111/119) underwent subsequent treatment in less than 1 year, 44 patients with Eastern Cooperative Oncology Group (ECOG) performance status $\geq 2$ and 76 patients suffered from symptoms. The mean longest diameter of RCC was $8.0 \pm 2.7 \mathrm{~cm}$ (range: 2.0-18.0). One hundred patients had undergone palliative nephrectomy and 19 received needle biopsy. Pathologically, 112 cases were confirmed as clear cell carcinoma (CCC), 2 of papillary car- 


\begin{tabular}{|c|c|c|c|c|}
\hline Variable number & Prognostic factors & Parameter & Number $(n=119)$ & $p$ value \\
\hline \multirow[t]{2}{*}{$\mathrm{X} 1$} & Targeting agent & Sorafenib & 37 & 0.911 \\
\hline & & Sunitinib & 82 & \\
\hline \multirow[t]{2}{*}{$\mathrm{X} 2$} & Gender & M & 92 & 0.729 \\
\hline & & $\mathrm{F}$ & 27 & \\
\hline \multirow[t]{2}{*}{ X3 } & Age (years) & $<70$ & 98 & 0.154 \\
\hline & & $\geq 70$ & 21 & \\
\hline \multirow[t]{2}{*}{$\mathrm{X} 4$} & Time from diagnosis to treatment (year) & $<1$ & 111 & 0.508 \\
\hline & & $\geq 1$ & 8 & \\
\hline \multirow[t]{2}{*}{$\mathrm{X} 5$} & ECOG PS & $<2$ & 75 & 0.000 \\
\hline & & $\geq 2$ & 44 & \\
\hline \multirow[t]{2}{*}{ X6 } & Symptom & No & 43 & 0.001 \\
\hline & & Yes & 76 & \\
\hline \multirow[t]{2}{*}{ X7 } & Longest diameter of RCC (cm) & $<7$ & 31 & 0.994 \\
\hline & & $\geq 7$ & 88 & \\
\hline \multirow[t]{2}{*}{$\mathrm{X} 8$} & Prior nephrectomy & No & 19 & 0.000 \\
\hline & & Yes & 100 & \\
\hline \multirow[t]{2}{*}{ X9 } & Pathology & $\mathrm{CCC}$ & 112 & 0.696 \\
\hline & & Non-CCC & 7 & \\
\hline \multirow[t]{2}{*}{$\mathrm{X} 10$} & Microscopic necrosis & No & 28 & 0.000 \\
\hline & & Yes & 91 & \\
\hline \multirow[t]{2}{*}{$\mathrm{X} 11$} & Number of metastatic sites & $<2$ & 74 & 0.000 \\
\hline & & $\geq 2$ & 45 & \\
\hline \multirow[t]{2}{*}{$\mathrm{X} 12$} & Lung metastasis & No & 46 & 0.400 \\
\hline & & Yes & 73 & \\
\hline \multirow[t]{2}{*}{$\mathrm{X} 13$} & Liver metastasis & No & 105 & 0.000 \\
\hline & & Yes & 14 & \\
\hline \multirow[t]{2}{*}{$\mathrm{X} 14$} & Bone metastasis & No & 92 & 0.000 \\
\hline & & Yes & 27 & \\
\hline \multirow[t]{2}{*}{$\mathrm{X} 15$} & Lymph node metastasis & No & 79 & 0.366 \\
\hline & & Yes & 40 & \\
\hline \multirow[t]{2}{*}{$\mathrm{X} 16$} & Pancreas metastasis & No & 114 & 0.000 \\
\hline & & Yes & 5 & \\
\hline \multirow[t]{2}{*}{$\mathrm{X} 17$} & Hemoglobin level & $<$ LLN & 41 & 0.040 \\
\hline & & $\geq$ LLN & 78 & \\
\hline \multirow[t]{2}{*}{$\mathrm{X} 18$} & Serum AKP level & $\leq U L N$ & 104 & 0.000 \\
\hline & & $>$ ULN & 15 & \\
\hline \multirow[t]{2}{*}{ X19 } & Corrected calcium level & $\leq U L N$ & 118 & 0.420 \\
\hline & & $>$ ULN & 1 & \\
\hline \multirow[t]{2}{*}{$\mathrm{X} 20$} & LDH level & $<1.5 \times$ ULN & 109 & 0.118 \\
\hline & & $\geq 1.5 \times U L N$ & 10 & \\
\hline \multirow[t]{2}{*}{$\mathrm{X} 21$} & Platelet level & $<$ LLN & 1 & 0.643 \\
\hline & & $\geq$ LLN & 118 & \\
\hline \multirow[t]{2}{*}{$\mathrm{X} 22$} & Blood WBC level & $<$ LLN & 2 & 0.572 \\
\hline & & $\geq$ LLN & 117 & \\
\hline$X 23$ & SSIGN Score & $6-10$ & 67 & 0.500 \\
\hline & & $\geq 10$ & 52 & \\
\hline$X 24$ & 1M-RDI & $<50 \%$ & 34 & 0.000 \\
\hline & & $\geq 50 \%$ & 85 & \\
\hline
\end{tabular}


cinoma, 2 of chromophobe RCC, 2 of sarcomatoid carcinoma, and 1 of collecting duct carcinoma. The mean hemoglobin level was $116.5 \pm 17.0 \mathrm{~g} / \mathrm{L}$ (female) and $134.8 \pm 22.7$ (male) (low limit of normal of hemoglobin: female $<115 \mathrm{~g} / \mathrm{L}$, male $<130 \mathrm{~g} / \mathrm{L}$ ). The mean serum alkaline phosphatase (AKP) level was $93.5 \pm 74.6 \mathrm{IU} / \mathrm{L}$ (range: $30.0-438.0$ ) (upper limit of normal AKP: $>126 \mathrm{IU} / \mathrm{L}$ ). The mean corrected calcium level was $2.2 \pm 0.2 \mathrm{mmol} / \mathrm{L}$ (range: $1.8-2.9$ ) (upper limit of normal corrected calcium: $>2.75 \mathrm{mmol} / \mathrm{L}$ ). The mean $\mathrm{LDH}$ level was $168.1 \pm 103.3 \mathrm{IU} / \mathrm{L}$ (range: 86.0-969.0) (1.5 upper limit of normal of AKP: >288 IU/L). The mean platelet level was $219.0 \pm 80.5 \times 10^{9} / \mathrm{L}$ (range: $76.0-612.0$ ) (the range of normal value of platelet: $100-300 \times 10^{9} / \mathrm{L}$ ). The mean blood white blood cell (WBC) level was $6.5 \pm 1.8 \times 10^{9} / \mathrm{L}$ $\left(2.5-15.5 \times 10^{9} / \mathrm{L}\right)$ (the range of normal value of blood WBC: $4.0-10.0 \times 10^{9} / \mathrm{L}$ ). The mean SSIGN (stage, size, grade, and necrosis) score was $9.1 \pm 2.1$ (range: $6.0-14.0$ ). In our study, 85 patients $(71.4 \%)$ attained a $1 \mathrm{M}$-RDI (relative dose intensity in the first month) of $\geq 50 \%$ for the targeting agent.

OS rates at year 1,3 , and 5 were $74 \%, 57 \%$, and $36 \%$, respectively; the median OS was 44.7 months. The treatment arms for the 2 targeting agents were well-balanced with respect to baseline characteristics, and the outcome (OS) was not significantly different between arms: OS was $25.0 \pm 18.6$ months for sorafenib and $21.6 \pm 14.1$ months for sunitinib $(p=0.276)$.

\section{Univariate analysis of prognostic factors for $\mathrm{OS}$}

From the 24 baseline clinical characteristics, univariate analysis identified a total of 11 statistically significant predictors of investigator-assessed OS (Table 1). Significant prognostic factors $(p<0.05)$ for shorter OS were: ECOG performance status $\geq 2$; symptoms; no prior nephrectomy; microscopic necrosis; number of metastatic sites $\geq 2$; presence of liver, bone, or pancreas metastasis; hemoglobin less than the lower limit of normal (LLN); and serum AKP greater than the upper limit of normal (ULN) among factors at initiation of targeted therapy, as well as the relative dose intensity of the targeting agent in the first month $(1 \mathrm{M}-\mathrm{RDI})$ of $<50 \%$.

\section{Multivariate analysis of prognostic factors for $0 S$}

Subsequent multivariate analysis found 4 baseline characteristics that were independently predictive for investigator-assessed OS in mRCC patients treated with sorafenib or sunitinib (Table 2). These 4 variables were: absence of symptoms, absence of bone metastasis, absence of pancreas metastasis, and targeting agent $1 \mathrm{M}-\mathrm{RDI}$ of $\geq 50 \%$. These additional independent significant predictors of OS did not include any of the 5 risk factors of the MSKCC model.

\section{Discussion}

Prognostic factors are essential in the design and interpretation of outcome data from clinical trials and for guiding routine patient care. We performed this analysis to identify and compare prognostic factors for OS in Chinese patients with $\mathrm{mRCC}$ treated with sorafenib or sunitinib as first-line therapy. Univariate analysis did not identify the targeting agent (sorafenib or sunitinib) as a significant predictor of investigator-assessed OS $(p=0.911)$. In contrast to other findings ${ }^{9}$ neither age nor gender was a prognostic factor for OS in our study. In this study, the OS rates at the end of the first, third, and fifth year were $74 \%, 57 \%$, and $36 \%$, respectively. These OS rates are lower than those reported in other studies..$^{2,10,11}$ The reason may be due in part to differences in the demographics of the patients enrolled. Most reports ${ }^{2,10,11}$ include patients with ECOG performance status 0 or 1 ; however, our study included 44 patients with ECOG performance status $\geq 2$. This phenomenon could reflect realworld variation in clinical data.

Univariate analysis of baseline clinical characteristics identified 11 statistically significant predictors $(p<0.05)$ of OS in patients treated with targeted therapy. Of these, only ECOG performance status and anemia were consistent with the prognostic factors in the MSKCC model; the other 3 factors in the MSKCC model (time from diagnosis to start of systemic therapy of $<1$ year and elevated levels of $\mathrm{LDH}$ and corrected serum calcium) were not identified as significant prognostic factors. These findings allude to the well-studied phenomenon that advances in technology and increased screening can have an effect on early diagnosis. ${ }^{12,13}$ For

\begin{tabular}{|c|c|c|c|c|c|c|c|c|}
\hline \multirow{2}{*}{ Prognostic factors } & \multirow{2}{*}{ B } & \multirow{2}{*}{ SE } & \multirow{2}{*}{ Wald } & \multirow{2}{*}{ df } & \multirow{2}{*}{ Sig. } & \multirow{2}{*}{$\operatorname{Exp}(B)$} & \multicolumn{2}{|c|}{ 95\% Cl $\operatorname{Exp}(\mathrm{B})$} \\
\hline & & & & & & & Lower & Upper \\
\hline Symptoms & 0.873 & 0.415 & 4.423 & 1 & 0.035 & 2.395 & 1.061 & 5.403 \\
\hline Bone metastasis & 0.728 & 0.363 & 4.021 & 1 & 0.045 & 2.071 & 1.017 & 4.220 \\
\hline Pancreas metastasis & 1.621 & 0.615 & 6.934 & 1 & 0.008 & 5.057 & 1.513 & 16.894 \\
\hline 1M-RDI <50\% & -2.926 & 0.543 & 28.996 & 1 & 0.000 & 0.054 & 0.018 & 0.156 \\
\hline
\end{tabular}

IM-RDI: relative dose intensity in the first month; $\mathrm{Cl}$ : confidence interval. 
example, with better imaging techniques, smaller tumours and metastasis are found with higher frequency, and as a result, disease is diagnosed earlier. In our study, almost all patients (111/119) underwent diagnosis with a strong sense of health, and underwent subsequent treatment in less than 1 year. This fact may be a reason that "time from diagnosis to start of systemic therapy of $<1$ year" was not identified as a significant prognostic factor. LDH and corrected serum calcium levels were also not identified as significant prognostic factors for OS. ECOG performance status is a comprehensive factor for health, and a better status would enhance a patient's tolerance towards the adverse effects of targeting agents. ECOG performance status was a significant predictor of OS in our study, which is consistent with the findings of other reports. ${ }^{14-17}$ In our study, 75 patients had ECOG performance status of 0 or 1 ; the median OS in this group was 21.8 months - a significant difference from the 12.1 months in the group with ECOG performance status $\geq 2(p=0.001)$.

Other significant pre-treatment prognostic factors included clinical symptoms at diagnosis, absence of prior nephrectomy, and $\geq 2$ metastatic sites. Luciani and colleagues reported that clinical symptoms at diagnosis were independent prognostic factors and not related to TNM staging or pathological grading..$^{18}$ In our study, 76 patients suffered symptoms at diagnosis. The median OS in the group with symptoms was 16.8 months versus 22.6 months in the group without symptoms $(p=0.020)$.

Prior nephrectomy was also a significant predictor of OS, and this was consistent with the clinical trial results from the Southwest Oncology Group (SWOG) and European Organisation for Research and Treatment of Cancer (EORTC). ${ }^{19,20}$ In our study, 100 patients had undergone palliative nephrectomy before targeted therapy. The median OS in the group with nephrectomy was 19.2 months versus 9.0 months in the group without nephrectomy $(p=0.024)$. This result demonstrates that palliative nephrectomy improves OS in mRCC patients treated with adjuvant targeted therapy.

The presence of $\geq 2$ metastatic sites, especially the presence of liver, bone, or pancreas metastasis, was a significant predictor of shorter OS. In our study, 45 patients had $\geq 2$ metastatic sites at diagnosis. The median OS in the group with $\geq 2$ metastatic sites was 12.0 months versus 21.1 months in the group with 1 metastatic site $(p=0.003)$. As for the metastatic site, lung and lymph node metastases did not significantly affect $\mathrm{OS}(p>0.05)$. In our study, lung metastasis was found in $61.3 \%(73 / 119)$ patients and was controlled with targeted therapy. With respect to bone metastasis, previous studies have shown mixed results, with bone metastasis identified as a significant prognostic factor in some but not all analyses; ${ }^{4,15,21-23}$ however, our study identified bone metastasis as a significant prognostic factor for OS $(p<0.05)$. The presence of liver or pancreas metastasis was identified as a significant prognostic predictor of shorter OS $(p<0.05)$.

The pathology was not a significant predictor of OS in our study. This may be associated with the number of enrolling patients and the fact that the inhibitory mechanisms of sorafenib and sunitinib target multiple pathways. Some reports from multicentre studies have stated that, with respect to OS, there was no significant difference between different pathology types and that the pathology type was not a significant prognostic factor compared with TNM stage and tumour grading. ${ }^{24,25}$ In our study, pathological assessment detected CCC in 112 patients. The median OS in the group with CCC was 17.9 months versus 13.1 months in the non-CCC group $(p=0.510)$. We also found that microscopic necrosis was detected in 91 patients. The median OS in the group with necrosis was 16.5 months versus 29.5 months in the group without microscopic necrosis $(p=0.020)$.

Several risk models have been developed to predict OS. ${ }^{26}$ Among them, the Leibovich risk model developed at the Mayo Clinic (the SSIGN system) aims to predict progression in RCC patients. ${ }^{27}$ This model uses primary tumour status, regional lymph-node status, tumour size, nuclear grade, and histologic tumour necrosis to stratify patients into low- (total score: 0-2), intermediate- (total score: 3-5), or high-risk (total score: $\geq 6$ ) of developing metastasis. In our study, the SSIGN score of all patients was $\geq 6$. We divided them into 2 arms (6-9 and $\geq 10)$ and found no significant difference $(p>0.05)$ with respect to OS. Therefore, a SSIGN score of $\geq 6$ was a high-level risk.

Although Kawashima and colleagues ${ }^{28}$ suggested that $1 \mathrm{M}$-RDI of $\geq 75 \%$ for the targeting agent was preferable for Asian patients, there is no evidence. In the present study, we could not determine the suitable initial dose of targeting agents. However, it was very important to maintain at least a half the dose of the targeting agents for the first month of therapy because a $1 \mathrm{M}-\mathrm{RDI}$ of $\geq 50 \%$ was one of the factors indicating favourable prognosis. In this study, 85 patients $(71.4 \%)$ attained a $1 \mathrm{M}-\mathrm{RDI}$ of $\geq 50 \%$, and the corresponding OS was $28.2 \pm 15.1$ months. However, the OS of the group with $1 \mathrm{M}-\mathrm{RDI}<50 \%$ was $8.9 \pm 4.5$ months $(p=0.000)$. We can therefore conclude that sorafenib and sunitinib at a $1 \mathrm{M}-\mathrm{RDI}$ of $\geq 50 \%$ might be tolerable in Chinese patients and results in a favourable prognosis.

In the multivariate analysis of OS in our study, 4 factors were independent predictors: absence of symptoms, absence of bone metastasis, absence of pancreas metastasis, and $1 \mathrm{M}-\mathrm{RDI}$ for targeting agents of $\geq 50 \%$. In a recent large retrospective study of prognostic factors for OS in patients receiving agents targeting vascular endothelial growth factor (VEGF), Heng and colleagues identified 4 of the 5 MSKCC risk criteria: hemoglobin, ECOG performance status, corrected calcium levels, and time from diagnosis to treat- 
ment. ${ }^{29}$ In addition to those 4 MSKCC risk factors, Heng and colleagues reported elevated absolute neutrophil count and elevated pre-treatment platelet count as independent predictive factors for OS. In our findings with sorafenib or sunitinib, neither serum LDH level nor corrected calcium level was identified as a prognostic factor for OS. The differences in clinical variables reported may reflect the specific factors examined and how they were coded or defined, differences in methodology, or differences in the specific patient populations studied

In this era of targeted therapy, there are some changes in the prognostic factors for $\mathrm{mRCC}$ and some prognostic factors are different from the traditional model (e.g., MSKCC model, Leibovich risk model). The reason for this disparity is not clear, but it may be due in part to the potential selection bias associated with the retrospective analysis, ethnic differences in the study populations, and heterogeneity in the clinicians' experiences of using sorafenib and sunitinib (these agents have only been available in China since 2007).

Our study has its limitations. One is that the patient sample comes from a single medical centre at the Ruijin Hospital. Another limitation is that our clinical trial was retrospective. Therefore, this analysis is suggestive, and further analyses on nationwide population-based datasets are needed.

\section{Conclusions}

Our findings detected prognostic factors for OS with sorafenib or sunitinib as first-line mRCC therapy in Chinese patients. The prognostic factors for $\mathrm{mRCC}$ have changed somewhat since the advent of targeted therapy and target drug (1M-RDI $\geq 50 \%$ ) play an important role in the prognosis of $\mathrm{mRCC}$. Continued progress in the identification of patient-specific prognostic factors for $\mathrm{mRCC}$ will require further advances in the understanding of tumour biology. One important direction of ongoing research is to identify a molecular signature of response to sorafenib, sunitinib and other targeting agents.

Competing interests: Dr. Zhao, Dr. Huang, Dr. Sun, Dr. Ma, Dr. Wang, Dr. Shao, Dr. Zhu, Dr. Zhou, Dr. Xu and Dr. Shen declare no competing financial or personal interests.

This paper has been peer-reviewed.

\section{References}

1. Motzer RJ, Bacik J, Murphy BA, et al. Interferon-alfa as a comparative treatment for clinical trials of new therapies against advanced renal cell carcinoma. J Clin Oncol 2002;20:289-96. http://dx.doi. org/10.1200/JC0.20.1.289

2. Motzer RJ, Hutson TE, Tomczak $P$, et al. Sunitinib versus interferon alfa in metastatic renal-cell carcinoma. N Engl J Med 2007;356:115-24. http://dx.doi.org/10.1056/NEJMoa065044
3. Motzer RJ, Bacik J, Schwartz LH, et al. Prognostic factors for survival in previously treated patients with metastatic renal cell carcinoma. J Clin Oncol 2004;22:454-63. http://dx.doi.org/10.1200/ $\mathrm{JC} 0.2004 .06 .132$

4. Motzer RJ, Bacik J, Mazumdar M. Prognostic factors for survival of patients with stage IV renal cell carcinoma: Memorial Sloan-Kettering Cancer Center experience. Clin Cancer Res 2004;10:6302S-3S. http://dx.doi.org/10.1158/1078-0432.CCR-040031

5. Mekhail TM, Abou-Jawde RM, Boumerhi G, et al. Validation and extension of the Memorial Sloan-Kettering prognostic factors model for survival in patients with previously untreated metastatic renal cell carcinoma. J Clin Oncol 2005;23:832-41. http://dx.doi.org/10.1200/JC0.2005.05.179

6. Molina AM, Motzer RJ. Current algorithms and prognostic factors in the treatment of metastatic renal cell carcinoma. Clin Genitourin Cancer 2008;6:s7-13. http://dx.doi.org/10.3816/CGC.2008.s.002

7. Bukowski RM, Negrier S, Elson P. Prognostic factors in patients with advanced renal cell carcinoma: Development of an international kidney cancer working group. Clin Cancer Res 2004;10:6310S-14S. http://dx.doi.org/10.1158/1078-0432.CCR-050000

8. Motzer RJ, Bukowski, Figlin RA, et al. Prognostic nomogram for sunitinib in patients with metastatic renal cell carcinoma. Cancer 2008; 113:1552-8. http://dx.doi.org/10.1002/cncr.23776

9. Patil S, Figlin RA, Hutson TE, et al. Prognostic factors for progression-free and overall survival with sunitinib targeted therapy and with cytokine as first-line therapy in patients with metastatic renal cell carcinoma. Ann Oncol 2011;22:295-300. http://dx.doi.org/10.1093/annonc/mdq342

10. Motzer RJ, Hutson TE, Tomczak P, et al. Overall survival and updated results for sunitinib compared with interferon alfa in patients with metastatic renal cell carcinoma. J Clin Oncol 2009;27:3584-90. http:// dx.doi.org/10.1200/JC0.2008.20.1293

11. Zhang H, Dong B, Lu JJ, et al. Efficacy of sorafenib on metastatic renal cell carcinoma in Asian patients: Results from a multicenter study. BMC Cancer 2009;9:249-56. http://dx.doi.org/10.1186/14712407-9-249

12. Bosl GJ, Geller NL, Chan EY. Stage migration and the increasing proportion of complete responders in patients with advanced germ cell tumors. Cancer Res 1988;48:3524-7.

13. Pfister DG, Wells CK, Chan CK, et al. Classifying clinical severity to help solve problems of stage migration in nonconcurrent comparisons of lung cancer therapy. Cancer Res 1990;50:4664-9.

14. Elson PJ, Witte RS, Trump DL. Prognostic factors for survival in patients with recurrent or metastatic renal cell carcinoma. Cancer Res 1988:48:7310-3.

15. Negrier S, Escudier B, Gomez F, et al. Prognostic factors of survival and rapid progression in 782 patients with metastatic renal carcinomas treated by cytokines: A report from the Groupe Français d'Immunothérapie. Ann Oncol 2002;13:1460-8. http://dx.doi.org/10.1093/annonc/mdf257

16. Ma C, Bandukwala S, Burman D, et al. Interconversion of three measures of performance status: An empirical analysis. Eur J Cancer 2010;46:3175-83. http://dx.doi.org/10.1016/i.eica.2010.06.126

17. Pencina MJ, D'Agostino RB. Overall C as a measure of discrimination in survival analysis: Model specific population value and confidence interval estimation. Stat Med 2004;23:2109-23. http://dx.doi. org $/ 10.1002 / \mathrm{sim} .1802$

18. Luciani $L G$, Gestari $R$, Tallarigo C. Incidental renal cell carcinoma-age and stage characterization and clinical implications: Study of 1092 patients (1982-1997). Urology 2000;56:58-62. http://dx.doi. org/10.1016/S0090-4295(00)00534-3

19. Mickisch GH, Garin A, van Poppel $\mathrm{H}$, et al. Radical nephrectomy plus interferon-alfa-based immunotherapy compared with interferon alfa alone in metastatic renal-cell carcinoma: A randomised trial. Lancet 2001;358:966-70. http://dx.doi.org/10.1016/S0140-6736(01)06103-7

20. Flanigan RC, Salmon SE, Blumenstein BA, et al. Nephrectomy followed by interferon alfa-2b compared with interferon alfa-2b alone for metastatic renal-cell cancer. N Engl J Med 2001;345:1655-9. http:// dx.doi.org/10.1056/NEJMoa003013

21. Royston P, Reitz M, Atzpodien J. An approach to estimating prognosis using fractional polynomials in metastatic renal carcinoma. Br J Cancer 2006:94:1785-8. http://dx.doi.org/10.1038/ si.bjc.6603192

22. Atzpodien J, Royston P, Wandert T, et al. Metastatic renal carcinoma comprehensive prognostic system. Br J Cancer 2003;88:348-53. http://dx.doi.org/10.1038/si.bic.6600768

23. Mani $\mathrm{S}$, Todd MB, Katz K, et al. Prognostic factors for survival in patients with metastatic renal cancer treated with biological response modifiers. J Urol 1995;154:35-40. http://dx.doi.org/10.1016/ S0022-5347(01)67218-5

24. Manola J, Royston P, Elson P, et al. Prognostic model for survival in patients with metastatic renal cell carcinoma: Results from the international kidney cancer working group. Clin Cancer Res 2011;17:5443-50. http://dx.doi.org/10.1158/1078-0432.CCR-11-0553

25. Patard JJ, Leray E, Rioux-Leclercq N, et al. Prognostic value of histologic subtypes in renal cell carcinoma: A multicenter experience. J Clin Oncol 2005;23:2763-71. http://dx.doi.org/10.1200/ JC0.2005.07.055 
26. Frank I, Blute ML, Cheville JC, et al. An outcome prediction model for patients with clear cell renal cell carcinoma treated with radical nephrectomy based on tumor stage, size, grade and necrosis: The SSIGN score. J Urol 2002;168:2395-400. http://dx.doi.org/10.1016/S0022-5347(05)64153-5

27. Leibovich $B C$, Blute $M L$, Cheville $J C$, et al. Prediction of progression after radical nephrectomy for patients with clear cell renal cell carcinoma: A stratification tool for prospective clinical trials. Cancer 2003;97:166371. http://dx.doi.org/10.1002/cncr.11234

28. Kawashima A, Takayama $\mathrm{H}$, Arai Y, et al. One-month relative dose intensity of not less than $50 \%$ predicts favourable progression-free survival in sorafenib therapy for advanced renal cell carcinoma in Japanese patients. Eur J Cancer 2011;47:1521-6. http://dx.doi.org/10.1016/i.ejca.2011.04.001
29. Heng DY, Xie W, Regan MM, et al. Prognostic factors for overall survival in patients with metastatic renal cell carcinoma treated with vascular endothelial growth factor-targeting agents: Results from a large multicenter study. J Clin Oncol 2009;27:5794-9. http://dx.doi.org/10.1200/JC0.2008.21.4809

Correspondence: Dr. Zhoujun Shen, No. 197, Ruijin 2nd Road, Shanghai 200025, China; shenzhoujun6@126.com 